Vol. 1, No. 1, Juni 2020

\title{
SPEKTA
}

Jurnal Pengabdian Kepada Masyarakat : Teknologi dan Aplikasi

Journal homepage :

http://journal2.uad.ac.id/index.php/spekta

\section{STRATEGI PEMASARAN USAHA KECIL MENENGAH PADA IBU- IBU AISYIAH MUHAMMADIYAH BALI}

\section{Tri Budiyanto*}

Program Studi Teknik Industri, Fakultas Teknologi Industri Universitas Ahmad Dahlan, Jl. Ringroad Selatan, Kragilan, Tamanan, Kec. Banguntapan, Bantul, Daerah Istimewa Yogyakarta, Indonesia

\begin{tabular}{l}
\hline INFO ARTIKEL \\
\hline \\
Diterima : Februari 2020 \\
Direvisi : April 2020 \\
Disetujui : Mei 2020 \\
\\
\hline
\end{tabular}

Keywords:

Marketing;

Strategy;

Small Medium Enterprise.

\begin{abstract}
Most of the Aisyiah womens in the Muhammadiyah Bali region have side jobs as housewives. Various businesses include Small Medium Enterprises (in Bahasa Indonesia, Usaha Kecil dan Menengah) engaged in grocery stalls, selling cloth, food stalls, furniture businesses, Muslim fashion stores and others. Some of the obstacles faced in developing their businesses include capitalization, management and location determination, as well as the quality of production as well as marketing. The purpose of this service activity is to equip Aisyiah Muhammadiyah Bali women in implementing marketing strategies that are in line with their business and competing in marketing. The benefits of this dedication for Aisyiah's mothers are getting knowledge and understanding related to the marketing field.
\end{abstract}

\section{PENDAHULUAN}

Ibu-ibu Aisyiah Wilayah Muhammadiyah Bali sebagian besar mempunyai pekerjaan sampingan usaha selain sebagai ibu rumah tangga. Berbagai usaha diantaranya UMKM yang bergerak dalam bidang warung kelontong, jualan kain, warung makan, usaha meubel, toko busana muslim dan lain sebagainya. Keberadaan UMKM saat ini menjadi hal yang tidak dapat dihindarkan dari masyarakat. Keberadaan UMKM sangat bermanfaat dalam perputaran roda keuangan di sektor informal. Selain itu UMKM juga dapat menciptakan kreatifitas yang dapat mempertahannkan unsur-unsur tradisi maupun kebudayaan di sekitar masyarakat setempat (Anggraeni, Hardjanto, dan Hayat, 2013).

Beberapa kendala yang dihadapi dalam mengembangkan usahanya diantaranya pemodalan, pengelolaan dan penentuan lokasi, maupun kualitas produksinya. Kualitas produksi ini merupakan kemampuan suatu produk untuk mempertahankan fungsinya termasuk durabilitas, reliablitas, ketepatan, kemudahan produk maupun reparasi dari produk tersebut (Harsalim, Sugiharto, Pemasaran, Petra, dan Siwalankerto, 2015). Selain

\footnotetext{
* Corresponding author.

E-mail address: tri.budiyanto@ie.uad.ac.id

https://doi.org/10.12928/J.spekta.v1i1.2649
} 
Vol. 1, No. 1, Juni 2020

itu rata-rata sebagian besar mengalami kesulitan dalam hal pemasaran. Pemasaran merupakan proses manajerial untuk mendapatkan apa yang dibutuhkan dan diinginkan dengan cara menciptakan, menawarkan, dan mempertukarkan produk yang bernilai dengan pihak lain (Diniaty dan Agusrinal, 2014).

Berlandaskan tujuan yang akan dicapai yaitu dapat memasarkan barang dagangannya dan mampu bersaing dengan penjual-penjual sejenis lainnya. Pada dasarkan UMKM sering dimasuki oleh pelaku karena faktor ketidak sengajaan sehingga tidak mengetahui pengetahuan tentang bagaimna menjalankan usaha sehingga akan menambah keuntungan (Bismala, 2016). Program pengabdian ini dirasa akan dapat memberi kontribusi. Dengan memahami strategi pemasaran secara baik diharapkan Ibu-ibu Aisyiah mampu menerapkan dalam usahanya yang selama ini digeluti. Tujuan kegiatan pengabdian ini adalah membekali Ibu-ibu Aisyiah Wilayah Muhammadiyah Bali dalam hal menerapkan strategi pemasaran yang sesuai dengan usahanya dan Berkompetisi dalam pemasaran

Manfaat pengabdian bagi ibu-ibu Aisyiah mendapatkan pengetahuan dan pemahaman yang terkait dengan bidang pemasaran. strategi pemasaran yang sesuai dengan usahanya selama ini. Adapun pengetahuan dan pemahaman yang dimaksud antara lain pengetahuan strategi pemasaran yang sesuai dengan usahanya selama ini.tentang dan kompetisi dalam pemasaran

\section{METODE PELAKSANAAN}

Metode yang dtierapkan dalam kegiatan pengabdian adalah berbentuk pelatihan untuk memberikan pengetahuan dan pemahaman tentang pemasaran dan tantangannya. Kegiatan dilaksanakan untuk mengatasi permasalahan yang terkait dengan pemasaran dengan melakukan penyuluhan. Materi yang diberikan diantaranya meliputi Pengertian Pemasaran, Manajemen Pemasaran dan Strategi Pemasaran untuk Usaha Kecil. Peserta kegiatan ini adalah Ibu-ibu Aisyiah Bali sebanyak 18 orang yang mayoritas pelaku usha kecil menengah

\section{HASIL DAN PEMBAHASAN}

Pengabdian amsyarakat ini dilakukan untuk memberikan penyuluhan mengenai strategi pemasaran untuk pelaku UKM yang ada di wilayah PRM Bali. Peserta penyuluhan ini merupakan ibu-ibu Aisyiah Bali. Kegiatan ini diikuti oleh 18 orang pelauk UKM dan dilaksanakn pada tanggal 12 Maret 2016 di Masjid Nurul Huda, Tuban Kabupaten Badung, Bali Pemasaran ini merupakan proses penyusunan komunikasi terpadu yang bertujuan untuk memberikan informasi mengenai barang atau jasa yang dapat memuaskan kebutuhan dan keinginan manusia. Salah satu kegiatan pokok yang perlu dilakukan oleh perusahaan (barang, jasa) dalam upaya untuk mempertahankan kelangsungan hidup usahanya.

Manajemen Pemasaran adalah salah satu kegiatan penting yang dilakukan oleh perusahaan (pengusaha kecil) untuk mempertahankan kelangsungan hidup perusahaannya, berkembang, dan mendapatkan laba. Proses pemasaran dimulai jauh sebelum barang- barang dibuat, dan tidak hanya berakhir dengan penjualan. Kegiatan pemasaran harus memberikan kepuasan kepada konsumen, untuk menjaga keberlangsungan usahanya, atau konsumen mempunyai pandangan yang lebih baik terhadap perusahaan (Yoka Roida, Sunarjanto, dan Jayaprana, 2010).

Pada penyuluhan ini ibu-ibu sangat antusias untuk menerima materi yang diberikan oleh Bapak Dr. Ir. Tri Budiyanto, M.T dari Prodi Teknik Industri Universitas Ahmad 
Vol. 1, No. 1, Juni 2020

Dahlan Yogyakarta. Penyuluhan ini dilakukan dengan 2 sesi, sesi pertama yaitu pemberian materi dan sesi kedua sesi tanya jawab. Proses penyuluhan pada sesi pertama dilakukan dengan meriah, pembicara beberapa kali memberikan candaan ringan sehingga kegiatan meriah dan tidak membosankan dapat dilihat pada Gambar 1

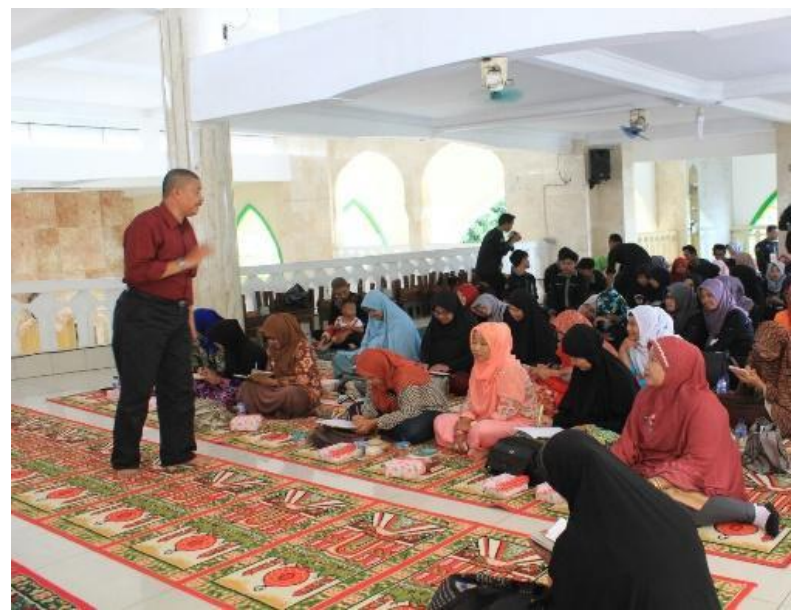

Gambar 1 Kegiatan saat penyuluhan

Pada sesi kedua dilakukan tanya jawab dan ibu-ibu begitu antusias untuk memberikan pertanyaan mengenai strategi pemasaran pada UMKM Gambar 2

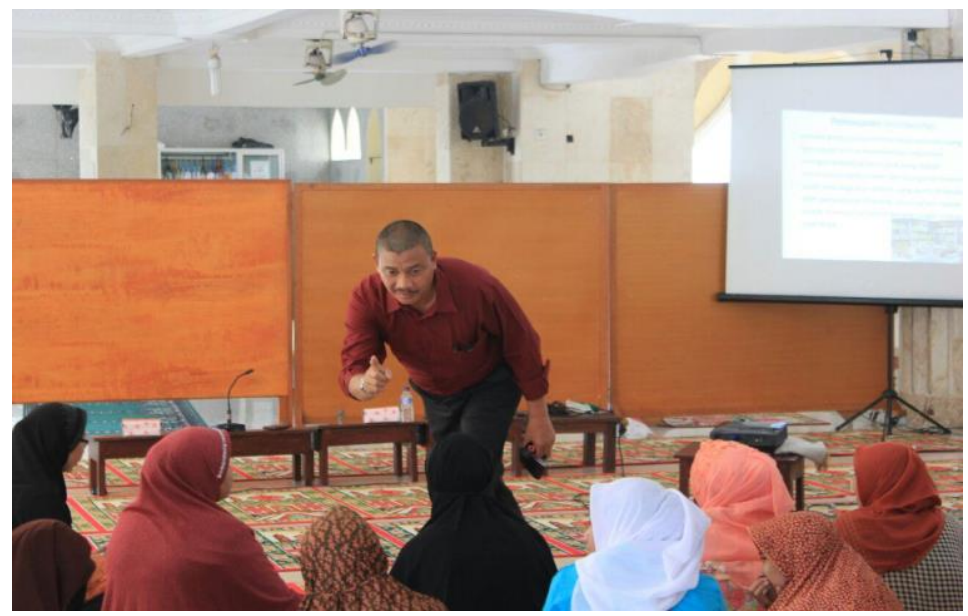

Gambar 2 Proses tanya jawab

Saran untuk pengabdian selanjutnya maka diperlukan pemanfaatan teknologi infromasi untuk pemasaran yang efektif. Pemahaman teknologi informasi menurut (Syaifudin, 2016) merupakan masalah yang kompleks karena adanya perbedaan karakteristik maupun perilaku dari pelaku UMKM dalam membangun strategi pemasaranya. Pertimbangan perilaku tersebut perlu mendapat perhatian khusus dalam konteks penerapan teknologi informasi. Selain masalah teknologi informasi maka diperlukan penyuluhan mengenai kebijakan dari pemerintah tentang UMKM . Permasalahan UMKM menurut (Hamid dan Susilo, 2015) kebijakan yang tepat diperlukan untuk pengembangan UMKM kedepanya. 
Vol. 1, No. 1, Juni 2020

\section{KESIMPULAN}

Dengan pelaksanakan kegiatan pengabdian masyarakat ini dapat disimpulkan bahwa peserta mampu membangkitkan motivasi peserta dalam memasarkan barang dagangannya. Mampu menumbuhkan semangat untuk bersaing secara kompetitif dalam pemasaran.

\section{DAFTAR PUSTAKA}

Anggraeni, F. D., Hardjanto, I., dan Hayat, A. (2013). Pengembangan usaha mikro, kecil, dan menegah (UMKM) melalui fasilitas pihak eksternal dan potensi internal. Jurnal Administrasi Publik, 1(6), 1286-1295.

Bismala, L. (2016). Model Manajemen Usaha Mikro Kecil dan Menengah (UMKM) untuk Meningkatkan Efektivitas Usaha Kecil Menengah. Jurnal Enterpreuner Dan Enterpreneurship, 5(1), 19-25.

Diniaty, D., dan Agusrinal. (2014). Perancangan Strategi Pemasaran Pada Produk Perancangan strategi pemasaran pada produk anyaman Pandan. Jurnal Sains, Teknoligi Dan Industri, Vol. 11, N(2), 2.

Hamid, E. S., dan Susilo, Y. S. (2015). Strategi Pengembangan Usaha Mikro Kecil Dan Menengah Di Provinsi Daerah Istimewa Yogyakarta*. Jurnal Ekonomi Pembangunan: Kajian Masalah Ekonomi Dan Pembangunan, 12(1), 45. https://doi.org/10.23917/jep.v12i1.204

Harsalim, R. R., Sugiharto, D. S., Pemasaran, P. M., Petra, U. K., dan Siwalankerto, J. (2015). Analisis Pengaruh Product quality, proce dan Promotion terhadap purchase intention mobil toyota alphard di Surabaya. Jurnal Manajemen Pemasaran, 3(1), 111.

Syaifudin, M. (2016). Analisa pengaruh privasi, keamanan dan kepercayaan terhadap niat untuk bertansaksi secara online di OLX.co.id. Jurnal Manajemen Pemasaran, 1-16.

Yoka Roida, H., Sunarjanto, N. A., dan Jayaprana, W. (2010). Internasionalisasi usaha mikro, kecil, dan menengah (umkm) ditinjau dari tipe kepemilikan: studi empiris di jawa timur. Jurnal Manajemen Teori Dan Terapan, (2), 158-170 
SPEKTA

Jurnal Pengabdian Kepada Masyarakat : Teknologi dan Aplikasi

Vol. 1, No. 1, Juni 2020

Halaman ini sengaja dikosongkan 